\title{
Twin foetus papyraceous in triplet pregnancy
}

\section{Gunjan Gulati*, Banashree Das, Deepika}

Department of Obstetrics and Gynaecology, VMMC and Safdarjung hospital, New Delhi, 110029

Received: 17 May 2015

Accepted: 6 June 2015

\author{
*Correspondence: \\ Dr. Gunjan Gulati, \\ E-mail: gunjan7565@gmail.com
}

Copyright: (c) the author(s), publisher and licensee Medip Academy. This is an open-access article distributed under the terms of the Creative Commons Attribution Non-Commercial License, which permits unrestricted non-commercial use, distribution, and reproduction in any medium, provided the original work is properly cited.

\begin{abstract}
The occurrence of twin papyraceous foetuses in triplet pregnancy is rare. A papyraceous foetus is found almost exclusively in multiple pregnancy. Papyraceous foetus is most frequent in foetuses dying between the third and sixth months of development. No convincing information has been obtained about the cause of early death of one or more foetuses and continued development of one or more others. There are rarely any symptoms or signs that suggest occurrence of foetus papyraceous, and a definite diagnosis can be made only at the time of delivery. Even then it may be missed by careless examination. We report here a case of a 25 year female with triplet pregnancy who delivered a healthy baby at term with two foetus papyracei.
\end{abstract}

Keywords: Foetus papyraceous, Triplet pregnancy

\section{INTRODUCTION}

Foetus papyraceous is defined as retention of a mummified parchment like remains of a dead foetus(es) in multiple pregnancy in association with a viable twin. ${ }^{1}$ Its incidence is 1 in 17,000-20,000 pregnancies or $2.3 \%$ of all twin pregnancies. ${ }^{1,2}$ The incidence of two foetuses papyraceous in a triplet pregnancy is 1 in $32,800 .{ }^{3}$ Disseminated intravascular coagulation (DIC) which complicates demise of singleton pregnancies especially if prolonged is uncommon with foetus papyraceous. ${ }^{4}$

\section{CASE REPORT}

A 25 year old female second gravida, para one with no living issue reported to gynae emergency of Safdarjung hospital at term with single live pregnancy in breech presentation in advanced second stage of labour and underwent a breech assisted vaginal delivery. Her previous pregnancy was an unsupervised pregnancy and a breech delivery was conducted by an untrained professional at home and a female baby expired during the process of birth. At the time of admission the history and general examination was unremarkable. The pulse rate was 86 beats per minute and her blood pressure was $120 / 80 \mathrm{mmHg}$. The fundal height was corresponding to period of gestation. The foetal heart rate was 142 beats per min. She was having good uterine contractions. Vaginal examination revealed cervix was fully dilated and fully effaced, membranes were absent, breech was felt $2 \mathrm{cms}$ below the ischial spines and pelvis was found to be adequate. Routine antenatal investigations like haemoglobin, total leucocyte count, differential count, platelet count, urine routine and microscopy, thyroid profile were within normal limits. Her HIV, HbsAg and VDRL status were negative. She had two ultrasound reports, one was done in the second trimester which revealed live triplet pregnancy each corresponding to 14 weeks 4 days with an anterior placenta. Another ultrasound was performed at 24 weeks which revealed a single live foetus with biometry corresponding to period of gestation with two collapsed sacs with dead foetuses with positive spalding sign suggestive of vanishing foetuses. As the patient came to us in advanced second stage of labour, she underwent an assisted breech vaginal delivery delivering a healthy boy baby of $2.25 \mathrm{~kg}$. 
Examination of the placenta showed two macerated foetuses in separate amniotic sacs (figure). She was discharged on the second postnatal day with her baby. Both had no complaints at the 6th week post-natal visit.

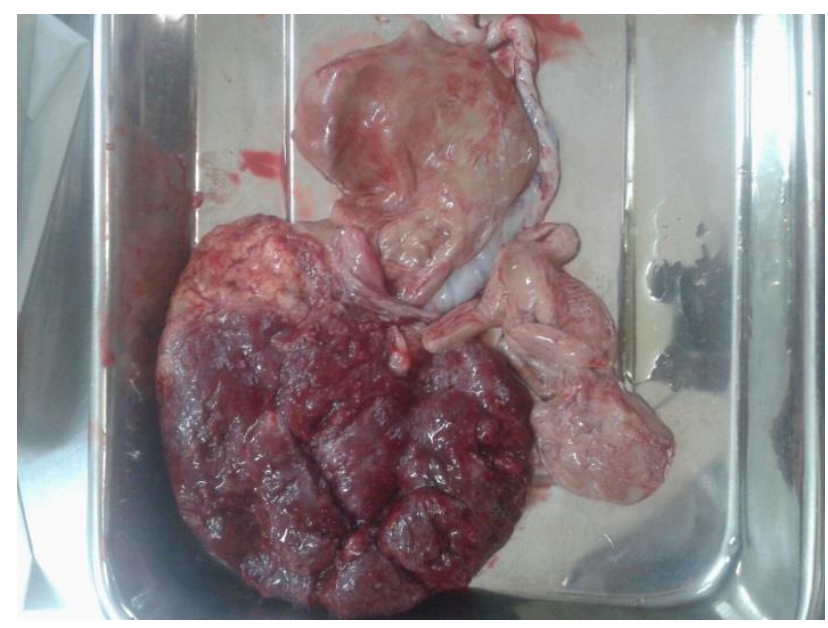

\section{DISCUSSION}

A vanishing twin is a foetus in a multi-foetal pregnancy which dies in utero and is either partially or completely reabsorbed by the surviving twin $^{5}$ and is sometimes referred to as twin embolization syndrome or vanishing twin syndrome (VTS). This dates back to 1980s when twin pregnancies were made visible early on by means of ultrasound. However at times, rather than being completely reabsorbed, the dead foetus is compressed by its growing twin to a flattened, parchment-like state known as foetus papyraceus. ${ }^{6}$ Vanishing twin dies either due to a poorly implanted placenta or due to some developmentally anomaly or a chromosomal defect which is incompatible with life.

Vanishing twins are frequently encountered in pregnancies resulting from IVF. Ultrasound scans are done very early in these pregnancies (5-8 weeks), so that, where a multiple conception has occurred, more than one amniotic sac can be seen easily in early pregnancy and a diagnosis of multiple gestation is confirmed, whereas a few weeks later there is only one amniotic sac to be seen and the other has "vanished".

Management of papyraceous twin with a live twin is challenging to the obstetricians. Various factors which may influence management of such a case are chronicity; gestational age at diagnosis and other complications specific to the pregnancy. $^{7}$ Ultrasound scan plays a pivotal role in the diagnosis of twin pregnancy and its complications. ${ }^{8}$

Maternal complications associated with foetus papyraceous include DIC, preeclampsia, hydramnious, antepartum haemorrhage, preterm labour and anemia. ${ }^{9,10}$ If the foetus is absorbed completely in the first trimester, there are usually no further complications to the pregnancy. ${ }^{11}$ However, if the event occurs after the first trimester, serious complications can occur which may include preterm labour, septicaemia and severe bleeding. Rarely at term, a low-lying foetus papyraceus may block the cervix necessitating a caesarean to deliver the living twin. The live twin of a vanishing twin pregnancy is also prone to cerebral palsy, renal failure, intrauterine or neonatal deaths. ${ }^{12,13}$ The possible mechanism may be transfer of thromboplastic proteins from the first twin to die to the other twin circulation, resulting in DIC. The other explanation may be that massive blood loss through vascular anastomosis may have taken place from the second twin to die into the first to die who had a more relaxed circulation. ${ }^{14}$ Feto-fetal transfusion imbalance may lead to foetal or infant death or cerebral palsy and/or congenital anomaly in surviving twins. ${ }^{15-17}$ Foetal death could also be a result of congenital malformations, umbilical cord prolapse or hydrops. ${ }^{9}$ The survivor in this triplet pregnancy had no obvious complications.

A foetal death in a multiple pregnancy with one or more normally surviving foetus is unusual. It is important to reassure the patient of the normal outcome expected in most of the cases. The diagnosis rests on the fact that multiple pregnancy is not missed during ultrasound examination. If possible delivery should be scheduled at a tertiary care centre. Good management of labour and thoroughly inspected placenta and membranes will permit the diagnosis of abnormalities and of foetus papyraceous.

\section{Funding: No funding sources Conflict of interest: None declared Ethical approval: Not required}

\section{REFERENCES}

1. Bush M, Pernoll ML. Multiple pregnancy. In: DeCherney AH, Nathan L, editors. Current Obstetric and Gynecologic Diagnosis and Treatment. New York: McGraw-Hill; 2003; 315-325.

2. Fusi L, Gordon H. Twin pregnancy complicated by single intrauterine death. Problems and outcome with conservative management. $\mathrm{Br} \mathrm{J}$ Obstet Gynaecol. 1990;97:511-6.

3. Hommel H, Festge B. Triplet pregnancy with papyraceous fetuses. Zentralbl Gynakol. 1979;101:845-7.

4. Teliga-Czajkowska J, Dadalska E, Sopliñski A. Triplet pregnancy complicated by intrauterine death of two fetuses: Case report. Ginekol Pol. 2003;74:1302-5.

5. Landy HJ, Weiner S, Corson SL, Batzer FR. The "vanishing twin": Ultrasonography assessment of fetal disappearance in the first trimester. Am J Obstet Gynecol. 1986;155(1):14-9.

6. Pelega D, Ferber A, Orvieto R, Bar-Hava I. Single intrauterine fetal death (fetus papyraceus) due to uterine trauma in a twin pregnancy. European Journal of Obstetrics \& Gynecology and Reproductive Biology. 1988;80 (2):175-6. 
7. Cleary-Goldman J, D'Alton M. Management of single fetal demise in a multiple gestation. Obstet Gynecol Surv. 2004;59:285-98.

8. Neilson JP, Hood VD, Cupples W, Gibson AA, Ferguson-Smith MA. Detection by ultrasound of abnormality in twin pregnancies during the second trimester. Br J Obstet Gynaecol. 1982;89:1035-40.

9. Borlum KG. Third-trimester fetal death in triplet pregnancies. Obstet Gynecol. 1991;77:6-9.

10. Bukar M, Audu BM, Sadauki HM, Elnafaty AU, Mairiga AG. Prevalence of iron deficiency and megaloblastic anemia at booking in a secondary health facility in northeastern Nigeria. Niger Med J. 2009;50:33-7.

11. Saidi MH. First-trimester bleeding and the vanishing twin. A report of three cases. J Reprod Med. 1988;33(10):831-4.

12. Ikpeze OC, Nwosu OB. Management of multiple gestations in which fetus papyraceous is a co-twin. Trop J Med Res. 1998;2:84-6.

13. Taylor CL, de Groot J, Blair EM, Stanley FJ. The risk of cerebral palsy in survivors of multiple pregnancies with cofetal loss or death. Am J Obstet Gynecol. 2009;201:41.e1-6.

14. Benirschke $K$. Intrauterine death of a twin: Mechanisms, implications for surviving twin, and placental pathology. Semin Diagn Pathol. 1993;10:222-31.

15. Larroche JC, Droullé P, Delezoide AL, Narcy F, Nessmann C. Brain damage in monozygous twins. Biol Neonate. 1990;57:261-78.

16. Gonen R. The origin of brain lesions in survivors of twin gestations complicated by fetal death. Am J Obstet Gynecol. 1991;165:1897-8.

17. Grafe MR. Antenatal cerebral necrosis in monochorionic twins. Pediatr Pathol. 1993;13:15-9.

Cite this article as: Gulati G, Das B, Deepika. Twin foetus papyraceous in triplet pregnancy. Int J Reprod Contracept Obstet Gynecol 2015;4:1214-6. 